\title{
What Went Wrong with the Achievement of Replacement Fertility in Bangladesh and Its Consequences on the Demographic Dividend: The Role of Proximate Determinants?
}

\author{
Ahbab Mohammad Fazle Rabbi ${ }^{*}$, Mohammed Kabir ${ }^{* *}$, Russell Kabir ${ }^{* *}$ \\ *Department of Statistical Sciences, University of Padua, Italy, fazlerabbi@stat.unipd.it \\ **Department of Statistics, Jahangirnagar University, Bangladesh, kabirm46@yahoo.co.uk \\ *** Department of Medical Science \& Public Health, Anglia Ruskin University, UK, \\ russell.kabir@anglia.ac.uk
}

\begin{abstract}
According to 2010 World Population Prospects (WPP), Bangladesh is passing the second phase of fertility transition. The recent fertility level (TFR) of Bangladesh is 2.3 births per woman. The Bangladesh Demographic \& Health Survey (BDHS)-2014 data showed that fertility is stalled again since BDHS-2011 unexpectedly. This stagnation raises questions about the prospect of reaching replacement fertility which was supposed to be achieved in Bangladesh by 2015 but failed again. This also has implications on the demographic window and consequently on the demographic dividend. Using the data of BDHS-2014 and applying the Bongaarts framework of the proximate determinants of fertility, this study attempts to identify the factors responsible for not achieving replacement fertility yet. The results demonstrate that contraception still dominates the fertility reduction in Bangladesh, followed by lactational infecundability, marriage and induced abortion. The change in the level of the proximate determinants and other key factors showed that fertility did not change much since BDHS-2011 which possibly caused this stagnation. The important factor which may have contributed to this is the high proportion of adolescent marriage in Bangladesh. This factor still creates a higher value of index of marriage which in turn affects fertility rates. Simulation on proportion married at adolescent age group suggests policy implications for achieving replacement fertility in Bangladesh can be achieved. In addition, the role of abortion and its measurement problem are also discussed
\end{abstract}

Keywords: Bangladesh, proximate determinants of fertility, nuptiality, fertility stagnation 
$104 \cdot$ Romanian Journal of Population Studies $・$ Vol. XII, No. 1

\section{Introduction}

Bangladesh is among the most densely populated countries in the world. Throughout the past century, the population of Bangladesh has increased exponentially. Between 2001 and 2011, 2 million individuals increased population figures yearly. According to 2010 World Population Prospects (WPP), fertility transition of a country is modelled in three Phases and they are(I) a high fertility, pre-transition phase (II) a fertility, transition phase and (III) a low fertility, post transition phase. These phases are based on level of Total Fertility Rate (TFR) of a country. The first phase is labelled as high fertility l; on the other hand, a sharp fall from TFR of 7.0 to below replacement level $(T F R=2.1)$ is defined as fertility transition. Bangladesh is now in the third phase of demographic transition. Once a country had reached convergence level, it would stabilize and continue at this point for certain period (UN, Department of Economic \& Social Affairs, Population Division, 2017). Thus, fertility level is one of the core components of population dynamics that determine the size, structure, and composition of the population in any country. Graphically, the fertility transition is described in WPP 2010 (Alkema et al. 2011), shown below (Figure1).

Figure 1. Different stages of fertility transition

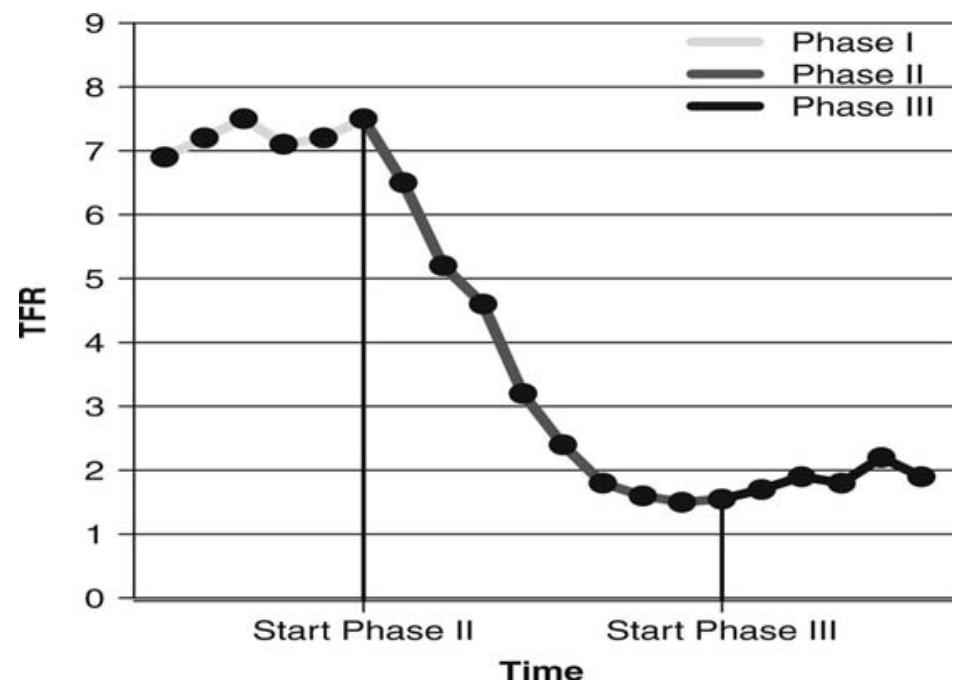

Phase I: Fertility is high and the fertility transition has not yet started

Phase II: Fertility transition

Phase III: Sub-replacement recovery

Source: Alkema et al. 2011: 819 
Due to fall in fertility, a country typically enjoys demographic dividend, a span of time in which the relative number of older people rises and younger population decreases. The results are dramatic increase in the share of working population. The result is a dramatic increase in the share of the population and opens the scope of the demographic window and leads to a "demographic dividend". It will turn into a demographic dividend only if the country invests heavily now in health, education, skills development, and employment generation, especially for the large number of youths.

The current total fertility rate (TFR) of Bangladesh is 2.3 births per woman which has stalled since last BDHS (BDHS-2014). Bangladesh aimed to achieve replacement TFR of 2.1 births per woman by 2015 through improved access to health and nutrition services for the poor and geographically marginalized population (BDHS-2011). The TFR declined from 6.3 births per woman in 1971-1975 to 5.1 births per woman in 1984-1988, followed by another rapid decline in the next decade of 1.8 births per woman to reach 3.3 births per woman in 1994-1996. TFR remained plateaued during the 1990s for about a decade, at around 3.3 births per woman. Since 2004 TFR has again begun to decline. The TFR declined further by one child per woman during the current decade to reach 2.3 births per woman in 2011 which continues till 2014. The trend of TFR from 1975 to 2014 is shown in the following graph (Figure 2).

Figure 2. Fertility trend in Bangladesh (1974-2014)

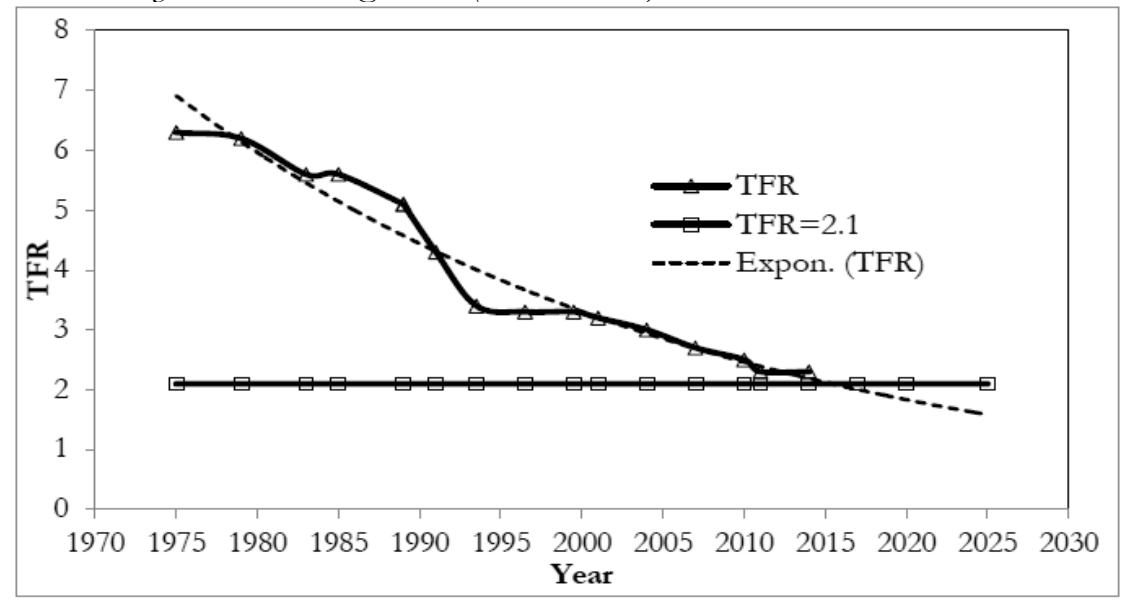

Note: The data are obtained from two World Fertility Surveys (BFS-1975\&1989), five Contraceptive prevalence surveys (during 1989-1991), six BDHSs (during 1993-2011) and two Maternal Mortality surveys (BMMS-2001\&2010). 
For the 1975 and 1989 BFS surveys, the rates refer to the 5-year period preceding the survey; for the other surveys, the rates refer to the 3-year period preceding the survey. The BFS and BDHS surveys utilized full birth histories, while the 1991 CPS used an 8-year truncated birth history. Source: 1975 BFS (MOHPC 1978: 73); 1989 BFS (Huq and Cleland 1990: 103); 1991 CPS (Mitra et al. 1993:34); BDHS 2014 (NIPORT).

The fertility projections are done using exponential regression of TFR against time, as Exponential model fitted the data with maximum goodness of fit compared to other kinds of regression approach. The fitted model is,

$$
\mathrm{TFR}=1 \mathrm{E}+26 \mathrm{e}^{-0.029 * \text { Year }} \text { with } \mathrm{R}^{2}=0.9567 .
$$

In Figure 2, the dashed green line represents the projected fertility level up to 2025, and red line presents the replacement level of fertility (TFR=2.1). The projection suggests that Bangladesh was supposed to achieve replacement level of fertility by 2015 if the trend continued. All subsequent governments that have come into power have identified population control as the top priority for government's population policy planning. This political commitment played a crucial role in the fertility decline in Bangladesh. Since 1980 the family planning program has emphasized the importance of integrating health and family planning services. The goal is to provide an essential integrated package of high quality, client-centered reproductive and child health care, family planning, communicable disease control, and curative services at a one-stop service point.

Many developing countries in Asia and Africa experienced the second phase of fertility transition without much socioeconomic development, on the other hand, countries at similar levels of economic development are often seen to show very different patterns of fertility pattern (Bongaarts and Watkins 1996). Past declines in the level of fertility across these countries were mostly attributed to a strong family planning program, in the absence of any remarkable change in socioeconomic status in a fundamentally traditional and impoverished society (Cleland et al. 1994). This statement is not consistent as many exceptions were held in 2000s. Also, the argument exists that change in other sectors of society and the economy might also play an important role on declining fertility (Caldwell et al. 1999). Few contradictory scenarios may be seen in Bangladesh, too. Though increase is observed in the level of using family planning method in the recent DHSs, still the relation between fertility level and contraceptive use prevalence are not well synchronized. The contraceptive prevalence rate (CPR) of 62 percent reflects a small rise from previous BDHS (BDHS-2014). 
As the relationship between fertility and its determinants is very complex and studying the determinants of fertility at aggregate level is not an easy task, because human reproduction is an outcome of both biological and behavioural factors, along with cultural and socioeconomic factors (Bongaarts and Potter 1983). The principal characteristic of biological and behavioural factors is that they can influence fertility directly, while socioeconomic and environmental factors affect fertility through modification of one or more biological or behavioural factors (Bongaarts 1978). Using data from 41 developed and developing countries, Bongaarts and Potter (1983) further observed that 96 percent of the variance in the total fertility rates of these populations could be explained by four principal proximate determinants: specifically, marriage, contraception, locational infecundability, and induced abortion. Because of these findings, the analysis of the determinants of fertility becomes more simplified since contribution of each factor can be estimated and policy strategy can be considered accordingly.

As these proximate determinants are well recognized for explaining aggregate fertility level, many researches exist till now for Bangladesh along with other developing and developed countries (Rabbi 2015; Islam et al. 2011; Mahjabeen and Khan 2011; Erfani and McQuillan 2008; Kabir and Chowdhury 2004; Islam et al. 1998, Islam and Islam 1993; Kabir and Uddin 1987; Wang et al. 1987). Most of these studies are done to explain current fertility level of specific country or countries, though many of them estimated the required level of contraceptive prevalence rate to achieve replacement level of fertility (Mahjabeen and Khan 2011). However, these approaches overlooked policy options regarding other proximate determinants which have perceived influence on fertility decline. Furthermore, with an inconsistent relationship between aggregate fertility levels and contraceptive prevalence rate, further indepth analysis on other proximate determinants is crucial for Bangladesh to ensure that Bangladesh is on right track to achieve the replacement level of fertility.

This unexpected stagnation near the replacement level of fertility draws attention to in-depth analysis to understand the phenomena of past decline as well as quality of birth history data. Since 2010, poverty declined considerably (BBS 2010) and per capita income along with females' enrolment at all level increased considerably. Female's participation in the labour market has also increased to a noteworthy degree in formal and informal sectors (BBS, 2010). Hence, to improve our understanding of the causes of fertility decline in Bangladesh, it is necessary to analyse how proximate determinants influence fertility. Keeping this in view, this paper investigates the levels and trends of 
the proximate determinants along with their key fertility intention behaviours in Bangladesh. This study provides a critical review of the major proximate determinants of fertility, and estimates their fertility-inhibiting effects using the Bongaarts (1978) model. Based on the above argument, the main objective of this paper is to assess why fertility remained stagnant from 2011 to 2014 again in Bangladesh.. We attempted to explore the reason behind this stagnation of fertility and as a result of which Bangladesh has failed to achieve replacement fertility in BDHS-2014. The purpose is also to identify which are the factors that policy makers should target for immediate intervention to reach the demographic goal. We also raise question regarding the possible effects of reducing adolescent marriages are reduced, and induced abortion data are used indirectly for determining future fertility change. The paper also investigates the implications on the demographic dividend.

\section{Methodology}

The data utilized for this research is a secondary data extracted from the Bangladesh Demographic and Health Survey conducted in 2014 under the authority of the National Institute for population Research and Training (NIPORT) of the Ministry of Health and Family Welfare and funded by USAID. The 2014 Bangladesh Demographic and Health Survey (BDHS) is a nationally representative sample survey designed to provide information on basic national indicators like fertility, childhood mortality, contraceptive knowledge and use, maternal and child health, nutritional status of mothers and children, and so on. BDHS-2014 contains 17,863 ever-married women of child bearing age of all the regions of Bangladesh.

To measure the fertility inhibiting effects of the four principal proximate determinants of fertility in a given population, the aggregate fertility model of Bongaarts (1978) and Bongaarts and Potter (1983) has been used in the current study. This model is an aggregate model and it assumes that the natural reproductive capacity, i.e. total fecundity rate (TF) of women is nearly the same for all women, but their actual reproductive performance is modified by four major proximate determinants. A population's actual level of fertility is measured by the total fertility rate (TFR), while in the absence of inhibiting effects of the proximate determinants, the fertility level of the population could reach a hypothetical maximum level, called total fecundity rate (TF). The observed level of fertility in a given population reflects the extent to which the proximate determinants reduce the TF. TF for Bangladesh is taken as 15.3 like the previous studies (Islam et al 1998, Islam and Islam 1993). The fertilityinhibiting effects of the four principal proximate determinants are proportion 
married, contraception, induced abortion, and postpartum infecundability and they are measured in the model by four indices: $C_{m}=$ index of marriage, $C_{c}=$ index of contraception, $C_{a}=$ index of induced abortion, and $C_{i}=$ index of postpartum infecundability. The value of each index lies between 0 and 1; 0 signifying complete fertility inhibition and 1 meaning no fertility inhibition. Symbolically, the relationship between the actual level of fertility in a population, as measured by total fertility rate (TFR) and the biological maximum $\mathrm{TF}$ is,

$$
\mathrm{TFR}=C_{m} \times C_{c} \times C_{a} \times C_{i} \times T F
$$

The complement of the value of an index is the proportionate reduction in fertility due to the inhibiting effect of that proximate variable.

\subsection{Estimation of the model Indices}

\subsubsection{Estimation of Index of Marriage, $C_{m}$}

The index of marriage is determined by the age-specific proportions of currently married among females. $C_{m}$ is estimated as the weighted average of the age-specific proportions of females currently married $m(a)$, with weights provided by the age-specific marital fertility rates $g(a)$. Symbolically,

$$
C_{m}=\frac{T F R}{T M F R}=\frac{\sum m(a) \times g(a)}{\sum g(a)}(2)
$$

\subsubsection{Estimation of Index of Contraception, $C_{c}$}

The effect of contraception on the risk of conception is measured by the index $C_{i}$. For current contraceptive prevalence rate $u$ and average use effectiveness $e$, the value of the index is calculated as

$$
C_{c}=1-1.08 \times u \times e(3)
$$

Where, $u$ is the current contraceptive prevalence rate (CPR) and $e$ is the average use-effectiveness of contraception, which is calculated as the weighted average of the following method-specific use-effectiveness levels (Bongaarts 1982).

\begin{tabular}{cc}
\hline Contraception method $u_{m}$ & Use-effectiveness $e_{m}$ \\
\hline Pill & 0.90 \\
Condom & 0.62 \\
IUD \& implants & 0.95 \\
Injection & 0.99 \\
Sterilization & 1.00 \\
Others & 0.70 \\
\hline
\end{tabular}

\footnotetext{
* Source: Bongaarts 1982
} 
This implies, $u=\sum u_{m}$ and $e=\frac{\sum u_{m} \times e_{m}}{u}$

The value 1.08 is the adjustment factor for sterilizing, on an assumption that all the contraceptive users may not be fecund at the time of using contraceptives and a small proportion of sterile women may use contraceptive without knowing their fecundity (Bongaarts and Potter 1983).

\subsubsection{Estimation of Index of lactational infecundability $C_{i}$}

The index of postpartum infecundability $C_{i}$ measures the effects of postpartum amenorrhoea and lactation (breastfeeding) on fertility. In the presence of breastfeeding and postpartum abstinence the average birth interval equals approximately 18.5 months plus the duration of postpartum infecundability (Bongaarts and Potter 1983). Thus, $C_{i}$ is estimated as,

$$
C_{i}=\frac{20}{18.5+i}(4)
$$

Where, $i$ is the average duration of post-partum infecundability. In current study, $i$ is considered as median. For average (median) duration of breastfeeding $B, i$ can be estimated from the following fitted model of Bongaarts and Potter (1983),

$$
i=1.753 e^{0.1396 \times B-0.001872 B^{2}} ; \text { Where, } R^{2}=0.96(5)
$$

\subsubsection{Estimation of index of abortion, $C_{a}$}

Abortion is not well reported in Bangladesh, so the index of abortion does not provide good results. The index of abortion $C_{a}$ is estimated as,

$$
C_{a}=\frac{T F R}{T F R+0.4 \times(1+u) \times T A}(6)
$$

Where $T A$ is the total abortion rate, estimated as the number of abortions in survey preceding three years divided by the number. of currently married women at that time. A termination of pregnancy after 8 weeks is considered as an abortion in current study (Johnston and Hill 1996).

\subsubsection{Stover's Review: inclusion of Index of Sterility, $C_{p}$}

This index is recommended later by Stover (1998) in his review of proximate determinants. This index is not suggested by the aggregate model of Bongaarts and Potter (1983), though the effect of sterility on fertility was discussed (Bongaarts and Potter 1983). The index of pathological sterility is intended to estimate the fertility-inhibiting effects of primary and secondary sterility. Since 
data on sterility were scarce at the time, Bongaarts later developed an equation to estimate the index as a function of primary sterility (Bongaarts 1984). The index is:

$$
C_{p}=\frac{7.63-0.11 \times s}{7.3}(7)
$$

Where, $s$ is the percentage of women aged 45-49 who have had no live births. This index is equal to 1.0 when 3 percent of women are childless at age 45-49. Anything above this level is assumed to be the effect of pathological sterility. The reason is, about 3 percent couples are sterile from the beginning of the reproductive period and consequently remain childless (Bongaarts and Potter 1983, Conception 1981). For Bangladesh, this index is omitted from analysis, since only 1.4 percent of women aged 45-49 were childless at survey preceding three years of BDHS-2014.

\subsection{Fertility-inhibiting effect}

The difference between the total fecundity (TF, taken as 15.3) and the predicted or model-estimated TFR demonstrate the resultant inhibitory effect of each determinant while, the fertility controlling effect is prorated by the product of difference between TF and model TFR to the proportion of the logarithm of each index to the sum of the logarithms of all indices (Wang et al. 1987). For example, the fertility inhibiting effect of marriage can be expressed symbolically as,

$$
[\text { TF }- \text { TFR }(\text { estimated })] \times \frac{\log C_{m}}{\log C_{m}+\log C_{c}+\log C_{i}+\log C_{a}}
$$

\section{Results}

\subsection{Role of major proximate determinants in fertility decline}

The summary measures required for the application of Bongaarts (1978) model and corresponding reproductive indicators for Bangladesh (BDHS-2014) are presented in the following table (Table 1). Multiplying all the indices together by the total fecundity rate of 15.3 produces the predicted TFR for the population. The predicted TFR typically differs from the observed TFR because of underreporting of births, measurement errors of the proximate determinants, or the omission of any other potential proximate determinants that are influential in determining fertility levels in that population under study (Islam et al. 2011).

Clearly, the lowest impact of marriage may be seen on recent fertility decline in Bangladesh; having a value of $0.888, C_{m}$ may reduce only 11 percent 


\section{$112 \cdot$ Romanian Journal of Population Studies $・$ Vol. XII, No. 1}

of the fertility in Bangladesh. The impact of family planning on current fertility is still a dominant factor for Bangladesh, as 59 percent of the fertility decline is attributed to use of contraception. Besides contraception, the highest fertility decrease is occasioned by post-partum infecundability, which reduces almost 51 percent of fertility for that index. The lowest effect of abortion is seen in fertility level, around 1 percent of fertility is reduced by abortion.

Table 1. Reproductive indicators and derived indices of proximate determinants of fertility for Bangladesh (BDHS-2014)

\begin{tabular}{lc}
\hline A. General Reproductive Indicators & \\
\hline TFR & 2.3 \\
TMFR & 2.59 \\
Median age at first marriage (25-49) & 15.8 years \\
CPR $(u)$ & 62.4 percent \\
Contraceptive use effectiveness $(e)$ & 0.87 \\
Median duration of breastfeeding & 31 months \\
Median duration of postpartum & 21.98 months \\
infecundability & \\
Total Abortion rate (TA) & 0.043 \\
\hline B. Model indices & \\
\hline$C_{m}$ & 0.888 \\
$C_{c}$ & 0.41 \\
$C_{a}$ & 0.988 \\
$C_{i}$ & 0.494 \\
\hline Combined effect of four determinants & 0.1777 \\
$\left(C_{m} \times C_{c} \times C_{a} \times C_{i}\right)$ & 15.3 \\
\hline Total fecundity $(\mathrm{TF})$ & $\mathbf{2 . 7 2}$ \\
\hline Predicted TFR & \\
\hline
\end{tabular}

Table 2 exhibits the magnitude of the total inhibiting effect being accounted for by each proximate determinant at BDHS-2014. For Bangladesh, out of 12.58 (=15.3-2.72) births being inhibited, 1.01 births (or 8 percent) were due to the marriage variable, 6.33 births (or 50 percent) were due to contraception, 0.07 births (or 0.5 percent) were due to abortion and 5.16 births (or 41 percent of total inhibiting effects) were because of post-partum infecundability.

The trends of four indices are summarized in the following table (Table 3). The estimated indices for BDHS 1993-94, 1996-97, 1999-2000, 2004 and 2007 are taken from the previous research (Islam et al. 2002; Mahjabeen and Khan 2011; Rabbi 2015). The differences between original and predicted TFR 
were high in earlier BDHSs, the lowest gap being observed for BDHS-2014. $C_{m}$ is unusually high in Bangladesh; lowest fertility decline occurs by marriage over the time. On the other hand, values of $C_{c}$ decreased sharply in all the BDHSs, which indicate the increasing trend of the use of family planning methods in Bangladesh. Generally the longer duration of breast feeding is also common in Bangladesh which is supported by $C_{i}$ index.

Table 2. Magnitude of the total fertility-inbibiting effect being accounted for each proximate fertility determinants for Bangladesh (BDHS-2014)

\begin{tabular}{cccc}
\hline $\begin{array}{c}\text { Proximate } \\
\text { determinants }\end{array}$ & Value of Index & \multicolumn{2}{c}{ Fertility-inhibiting effect } \\
\cline { 3 - 4 } & & $\begin{array}{c}\text { Reduction of births } \\
\text { per woman }\end{array}$ & $\begin{array}{c}\text { Percentage } \\
\text { reduction }\end{array}$ \\
\hline$C_{m}$ & 0.888 & 0.86 & 6.83 \\
$C_{c}$ & 0.41 & 6.49 & 51.58 \\
$C_{a}$ & 0.988 & 0.09 & 0.72 \\
$C_{i}$ & 0.494 & 5.13 & 40.77 \\
\hline Total [TF-TFR(est)] & 12.58 & 12.57 & 100.0 \\
\hline
\end{tabular}

Table 3. Trends of proximate determinants of fertility in Bangladesh (1993-2014)

\begin{tabular}{cccccccc}
\hline BDHS & TFR & $\boldsymbol{C}_{\boldsymbol{m}}$ & $\boldsymbol{C}_{\boldsymbol{c}}$ & $\boldsymbol{C}_{\boldsymbol{i}}$ & $\boldsymbol{C}_{\boldsymbol{a}}$ & $\begin{array}{c}\text { Predicted } \\
\text { TFR }\end{array}$ & $\begin{array}{c}\text { TFR-TFR } \\
\text { (est) }\end{array}$ \\
\hline $1993-94$ & 3.4 & 0.878 & 0.575 & 0.660 & 1.0 & 5.10 & 1.70 \\
$1996-97$ & 3.3 & 0.858 & 0.531 & 0.680 & 1.0 & 4.74 & 1.44 \\
$1999-2000$ & 3.3 & 0.843 & 0.495 & 0.714 & 1.0 & 4.56 & 1.26 \\
2004 & 3.0 & 0.743 & 0.454 & 0.813 & 0.963 & 4.04 & 1.04 \\
2007 & 2.7 & 0.750 & 0.489 & 0.823 & 0.959 & 4.43 & 1.73 \\
2011 & 2.3 & 0.871 & 0.42 & 0.493 & 0.991 & 2.73 & 0.43 \\
2014 & 203 & 0.888 & 0.41 & 0.494 & 0.988 & 2.72 & 0.42 \\
\hline
\end{tabular}

Note: Values of proximate determinants for first three BDHSs are taken from Islam et al (2002); BDHS-2004 and 2007 are taken from Mahjabeen and Khan (2011) and BDHS2011 are taken from Rabbi (2015). For BDHS-2004 and 2007 an index of abortion is constructed using data on abortion from the Matlab study (ICDDR,B 1996), which is used as a proxy (Mahjabeen and Khan 2011).

To determine the reason of this stagnation in fertility level, we compared all the fertility indicators with that of BDHS-2011 as well. The summary measures of Bongaarts (1978) model and corresponding reproductive indicators for 
114 Romanian Journal of Population Studies • Vol. XII, No. 1

Bangladesh during BDHS 2011 and BDHS 2014 are summarized in the following table (Table 4).

As evident from the various proximate determinants, the change in the level of the reproductive indicators did not occur much in the BDHS-2014 compared to the BDHS-2011 which may be the reason for not achieving replacement level of fertility. We explored each of these indicators with associated formal proximate determinants in the following sections, and by creating simulation we tried to show what should be prioritized in future

Table 4. Comparison of reproductive indicators and derived indices of proximate determinants of fertility for Bangladesh (BDHS 2014 and BDHS 2011)

\begin{tabular}{lcc}
\hline General Reproductive Indicators & BDHS-2014 & BDHS-2011 \\
\hline TFR & 2.3 & 2.3 \\
TMFR & 2.59 & 2.64 \\
Median age at first marriage (25-49) & 15.8 years & 15.5 years \\
CPR $(u)$ & 62.4 percent & 61.2 percent \\
Contraceptive use effectiveness $(e)$ & 0.87 & 0.88 \\
Median duration of breastfeeding & 31 months & 31.2 months \\
Median duration of Post-partum infecundability & 21.98 months & 22.08 months \\
Total Abortion rate (TA) & 0.043 & 0.028 \\
\hline B. Model indices & & \\
\hline$C_{m}$ & 0.888 & 0.871 \\
$C_{c}$ & 0.41 & 0.42 \\
$C_{a}$ & 0.988 & 0.991 \\
$C_{i}$ & 0.494 & 0.493 \\
\hline Combined effect of four determinants & 0.1777 & 0.1787 \\
$\left(C_{m} \times C_{c} \times C_{a} \times C_{i}\right)$ & & \\
\hline Total fecundity (TF) & 15.3 & 15.3 \\
\hline Predicted TFR & $\mathbf{2 . 7 2}$ & $\mathbf{2 . 7 3}$ \\
\hline
\end{tabular}

\subsection{Marriage}

It has already been noted that impact of marriage on fertility decline is not significant which is due to the high prevalence of adolescent marriages. The estimated value of the index suggests that there is a little gap for younger ages and consequently the difference between TFR and TMFR (marital fertility rate) is also low. This high value of index of marriage occurs due to higher proportion of adolescents' marriage in Bangladesh. The age specific fertility rate (ASFR), age specific marital fertility rate (ASMFR) and the proportion 
married for BDHS 2014 in all age groups are presented in the following table (Table 5).

Table 5. ASFR, ASMFR and proportion married for Bangladeshi women (BDHS-2014)

\begin{tabular}{ccccc}
\hline Age group & $\begin{array}{c}\text { Proportion } \\
\text { married }^{*}\end{array}$ & ASFR & ASMFR & $\begin{array}{c}\text { Median age } \\
\text { at marriage** }\end{array}$ \\
\hline $15-19$ & 0.442 & 113 & 0.442 & - \\
$20-24$ & 0.830 & 143 & 0.830 & 17.2 \\
$25-29$ & 0.920 & 110 & 0.920 & 16.4 \\
$30-34$ & 0.946 & 57 & 0.946 & 16.0 \\
$35-39$ & 0.923 & 24 & 0.923 & 15.6 \\
$40-44$ & 0.890 & 4 & 0.890 & 15.3 \\
$45-49$ & 0.855 & 5 & 0.855 & 15.3 \\
\hline Total & 0.798 & TFR $=2.3$ & TMFR $=2.59$ & $\mathbf{1 5 . 5}$ \\
\hline
\end{tabular}

Notes: * Bongaarts multiplier is applied. ASMFR for 15-19 is computed as $0.75 \times$ ASMFR for women 20-24 (Bongaarts and Potter 1983).

** The age at first marriage is defined as the age at which the respondent began living with her first spouse/partner. Median age at marriage for women aged 25-49 is 15.5 years. For women aged 20-49, the median age at marriage is 15.8 years. Median age at marriage is not applicable for age group 15-19 due to censoring.

Age at first marriage has a major effect on childbearing because the risk of pregnancy depends primarily on the age at which women first marry (Islam et al 1998). Women who marry early, on average, are more likely to have their first child at a young age and give births to more children overall, contributing to higher fertility (Islam and Islam 1993). For BDHS 2014, 80 percent of women aged 15-49 were married at the time of survey. Among them, about 44 percent of women aged 15-19 were married, which affects age specific marital fertility rate at adolescent ages. A few important indicators of marriage in Bangladesh are presented in the following Table (Table 6). Compared to early BDHSs, median age at first marriage increased slightly in Bangladesh in the last twenty years with highest value at BDHS 2014. The rate did not increase with a secular trend, as a decrease may be observed in 1996-97 and 2004. It should be noted that, the lowest median age at first marriage is observed in Bangladesh compared to the neighbouring South Asian countries during BDHS 2011.

Age specific fertility rates for women aged 15-19 have a sharp decline since BDHS-1996-97. After an increase in BDHS-1996-97, it falls steadily to at 113 at BDHS-2014. Despite this the contribution of adolescent age specific 
116 Romanian Journal of Population Studies • Vol. XII, No. 1

fertility to the total fertility is about 25 percent. To achieve replacement level of fertility, adolescent marriage should get priority in the policy if we want to achieve our demographic objective.

Table 6. Trends of few marriage indicators of Bangladesh (BDHS-1993-94 to 2014)

\begin{tabular}{ccccc}
\hline BDHS & $\begin{array}{c}\text { Proportion } \\
\text { married (all) }\end{array}$ & $\begin{array}{c}\text { Proportion } \\
\text { Married (15- } \\
\text { 19) }\end{array}$ & $\begin{array}{c}\text { ASFR } \\
\text { (15-19) }\end{array}$ & $\begin{array}{c}\text { Median age at } \\
\text { first marriage } \\
\text { (20-49) }\end{array}$ \\
\hline $1993-94$ & 79.4 & 47.7 & 140 & 14.4 \\
$1996-97$ & 77.6 & 48.3 & 147 & 14.2 \\
$1999-2000$ & 76.2 & 46.6 & 144 & 15.0 \\
2004 & 77.1 & 46.0 & 137 & 14.8 \\
2007 & 78.0 & 45.6 & 126 & 15.3 \\
2011 & 80.0 & 44.7 & 118 & 15.8 \\
2014 & 79.8 & 44.2 & 113 & 15.8 \\
\hline
\end{tabular}

\subsection{Contraception}

BDHS surveys defined current use of contraception as the proportion of currently married women who report that they are using a family planning method at the time of the survey (BDHS 2014). The contraceptive prevalence rate is high in Bangladesh (BDHS 2014). With 62.4 percent contraceptive prevalence rate (CPR), more than half of the currently married women aged 15-49 use a modern method of contraception (52 percent). Use effectiveness of 87 percentages is seen for contraceptives in the current study (Table 1), which is high enough for a developing country (Simmons 1985). Also the value of $C_{c}$ is 0.41 along with reduction of 6.49 births per woman (Table 2). Increasing the family planning method more effectively will reduced the fertility level of Bangladesh, as has also been suggested in previous studies (Islam et al. 1998). The trends of using modern family planning methods for the seven BDHSs are summarized in the following table (Table 7). CPR of 62 percent reflects a slight increase in FP utilization compared to previous BDHS. Between 1993 and 2011 the use of female sterilization among currently married women declined from 8.2 to 4.6 percent. At the same time, two methods gained popularity; the pill is being used by 27 percent of women (BDHS 2011), compared to 17 percent at 1993 and injectables (4.6 percent in 1993 to 11 percent in 2011). 
Table 7. Trends of modern family planning methods in Bangladesh (1993-2014)

\begin{tabular}{cccccccccc}
\hline BDHS & $\begin{array}{c}\text { Any } \\
\text { modern } \\
\text { method }\end{array}$ & Pill & IUD & $\begin{array}{c}\text { Inject } \\
\text { ions }\end{array}$ & $\begin{array}{c}\text { Con- } \\
\text { dom }\end{array}$ & $\begin{array}{c}\text { Female } \\
\text { sterilia- } \\
\text { tion }\end{array}$ & $\begin{array}{c}\text { Male } \\
\text { steriliza } \\
\text {-tion }\end{array}$ & $\begin{array}{c}\text { Impl } \\
\text { ants }\end{array}$ & CPR \\
\hline $1993-94$ & 36.6 & 17.5 & 2.2 & 4.6 & 3 & 8.2 & 1.1 & - & 44.9 \\
$1996-97$ & 42.1 & 21.1 & 1.8 & 6.3 & 3.9 & 7.7 & 1.1 & 0.1 & 49.8 \\
$1999-00$ & 44 & 23.3 & 1.3 & 7.3 & 4.3 & 6.8 & 0.5 & 0.5 & 54.3 \\
2004 & 47.6 & 26.4 & 0.6 & 9.8 & 4.2 & 5.3 & 0.6 & 0.8 & 58.5 \\
2007 & 47.5 & 28.5 & 0.9 & 7 & 4.5 & 5 & 0.7 & 0.7 & 55.8 \\
2011 & 52.1 & 27.2 & 0.7 & 11.2 & 5.5 & 5 & 1.2 & 1.1 & 61.2 \\
2014 & 54.1 & 27.0 & 0.6 & 12.4 & 6.4 & 4.6 & 1.2 & 1.7 & 62.4 \\
\hline
\end{tabular}

\subsection{Lactational infecundability}

5.13 births were being inhibited (or almost 41 percent of total inhibiting effects) due to the effect of post-partum infecundability (Table 2). Information on breastfeeding in the BDHS 2014 was collected on all children born during the last three years preceding the survey date. This data includes children living and deceased at the time of the survey. The median duration of any breastfeeding among Bangladeshi children in BDHS-2014 is 31 months which consequently implies almost 22 months of median duration at post-partum infecundability. The median duration of exclusive breastfeeding is estimated at 2.8 months in BDHS 2014. The median duration of exclusive breastfeeding has decreased since 2011 (BDHS 2014). Generally longer breastfeeding is common in Bangladesh. The median duration of breastfeeding in Bangladesh was extraordinarily long during BDHS-1993-94. It was so long, in fact, that it was not possible to be calculated exactly from BDHS 1993-94 data. This is because breastfeeding status was asked only for children age 35 months or less and 60 percent of the children ages 34-35 months were still being breastfed.

\subsection{Induced abortion}

Abortion is illegal and strictly prohibited by law in Bangladesh, unless otherwise recommended by registered doctors (Islam et al. 1998). Fertility reduced by abortion is very low Bangladesh (approximately 0.1 percent), possibly due to misreported abortion rates. In earlier research, the index of abortion is assumed to be 1.0 due to the very low number of reported abortions, though several studies on abortion suggest that it is not rare in Bangladesh (ICDDR,B 1996). The gap between observed and predicted TFR may also arise due to abortion, as further analysis on abortion rates may conclude more precisely (Johnston and Hill 1996). In most cases, abortion is done under the name of menstrual regulation, a procedure which is approved 
118 - Romanian Journal of Population Studies • Vol. XII, No. 1

by the government's health and family planning program (Islam et al. 1998). Distribution of terminated pregnancies during the last three years preceding BDHS 2014 is summarized in the following table (Table 8).

Table 8. Distribution of terminated pregnancies (both MR and Abortions) in Bangladesh (BDHS 2011)

\begin{tabular}{ccc}
\hline $\begin{array}{c}\text { Month pregnancy } \\
\text { terminated }\end{array}$ & No. of observations & Percentage \\
\hline 1 & 53 & 6.1 \\
2 & 86 & 10.0 \\
3 & 75 & 8.7 \\
4 & 63 & 7.2 \\
5 & 64 & 7.4 \\
6 & 88 & 10.1 \\
7 & 76 & 8.8 \\
8 & 74 & 8.6 \\
9 & 287 & 33.1 \\
\hline Total & 866 & 100.0 \\
\hline
\end{tabular}

During BDHS 2014, a total of 866 terminated pregnancies occurred during three years preceding survey date. Among them 727 terminations (84 percent) occurred after 8 weeks of conception, which gave a total abortion rate of 0.043 . $C_{a}$ is 0.988 , which means approximately 1 percent fertility may be reduced by induced abortions. Indirect techniques are suggested in many studies to estimate abortion rate for countries where abortions are misreported; i.e. to estimate $C_{a}$ from the values of other proximate determinants of fertility (Johnston and Hill 1996). If we consider Ca is 0.95 then reduction of fertility contributed by the induced abortion will be higher than the current estimate suggests. Due to social, cultural and religious stigma, induced abortion is heavily underestimated.

\subsection{Role of proximate determinants to achieve replacement level fertility} The sudden stagnation at 2.3 births in BDHS 2014 is supposed to be unexpected as the fertility was falling exponentially during the previous surveys (Figure 2). From the findings of the current study, it is clear that, to achieve replacement level of fertility, further decline is required for proximate determinants. The required level of index of contraception and lactational infecundability are estimated in the following sections along with simulation for marriage. We are not considering the induced abortion because the 
abortion is severely misreported in BDHSs data, which seriously affect the abortion rates used in Bongaarts framework

\subsection{Contraception}

For reaching replacement level of fertility without any change in other proximate determinants rather than family planning, the required level of contraceptive prevalence rate (CPR) is obtained using equation (3). Suppose that $T F R_{1}$ and $T F R_{2}$ be the observed total fertility rate and 2.1 (TFR for replacement level fertility) respectively and let the corresponding levels of contraceptive prevalence and use-effectiveness be $u_{1}$ and $e_{1}$, and $u_{2}$ and $e_{2}$ respectively. If we assume that the indices for all other proximate determinants except for contraception remain constant, i.e., $C_{m 1}=C_{m 2}, C_{a 1}=C_{a 2}, C_{i 1}=C_{i 2}$, $T F_{1}=T F_{2}$ then obviously

$$
\begin{gathered}
\frac{T F R_{2}}{T F R_{1}}=\frac{C_{C 2}}{C_{C 1}}=\frac{1-1.08 \times u_{2} \times e_{2}}{1-1.08 \times u_{1} \times e_{1}} \\
\text { Thus, } u_{2}=\frac{1}{\left(1.08 \times e_{2}\right)} \times\left[1-\frac{T F R_{2}}{T F R_{1}} \times C_{C 1}\right]
\end{gathered}
$$

For BDHS 2014, $C_{c}$ was 0.41 and TFR was 2.3. Assuming use-effectiveness is unchanged $\left(e_{1}=e_{2}=0.873\right)$, we have $u_{2}$ as 0.6636 . Therefore, 66.36 percent $\mathrm{CPR}$ is required to achieve replacement level of fertility.

\subsection{Lactational infecundability}

The required duration of post-partum infecundability may be estimated using equation (4). Continuing with symbols of contraception and assuming that the indices for all other proximate determinants except for breastfeeding remain constant, i.e., $C_{m 1}=C_{m 2}, C_{a 1}=C_{a 2}, C_{c 1}=C_{c 2}, T F_{1}=T F_{2}$ then obviously

$$
\frac{T_{F R}}{T F R_{1}}=\frac{C_{i 2}}{C_{i 1}}=\frac{\frac{20}{18.5+i_{2}}}{\frac{20}{18.5+i_{2}}}
$$

Here, $i_{1}$ and $i_{2}$ are corresponding duration of post-partum infecundability for $T F R_{1}$ and $T F R_{2}$. Then the required duration of post-partum infecundability to achieve replacement level of fertility will be, 


$$
i_{2}=\left[\frac{20}{\frac{T F R_{2}}{T F R_{1}} \times C_{i 1}}\right]-18.5
$$

For BDHS-2014, estimated $C_{i 1}$ was 0.494 , which implies that a median duration of post-partum infecundability of 25.84 months is required to achieve replacement level of fertility.

\subsection{Marriage}

It was already stated that, among all the indices, reduction in fertility contributed to by the proportion of married is at a minimum, which is due to the high prevalence of adolescent marriage in Bangladesh. In Bangladesh still one fifth of the total fertility is attributed to the adolescents despite the fact legal age at marriage is 18 years. Unlike previous two indicators, the required level of marriage can't be determined from estimated $C_{m}$. It will also not imply anything for the policy-makers. A simulation is performed to assess what would be necessary to reach the desired goal of replacement fertility, and the following Table shows that if the proportion of married individuals aged 15 to 19 is brought down from the current $44 \%$ to $36 \%$ Bangladesh can easily achieve replacement level of fertility.

Suppose with 0.442 proportion married at age group 15-19, we have ASMFR of 129 while ASFR was 113 for age 15-19. Here ASMFR was estimated using Bongaarts multiplier on ASMFR of the next age group (Bongaarts and Potter 1983). Due to the short average of marital duration, the marital fertility rates for women aged 15-19 years, therefore, do not represent the potential fertility of the whole age group. In this case Bongaarts recommends that the marital fertility rate for women aged 15-19 be taken as 0.75 of the rate for women aged 20-24 (Bongaarts and Potter 1983). In this simulation, Bongaarts multiplier is omitted to check the basic contribution of adolescents on fertility. Instead of Bongaarts multiplier, the adjusted ASMFR, TMFR, $C_{m}$ and model TFR are 255, 3.25, 0.714 and 2.18 respectfully. The results of the simulated ASMFR, TMFR, $C_{m}$ and model TFR for various level of proportion married at age 15-19 are summarized in the following table (Table 9).

The simulation shows that the aggregate fertility level will decline along with the decrease in the level of adolescent marriages. The fall in ASMFR, TMFR, $C_{m}$ and model TFR almost followed a linear trend with the fall in 
proportion of individuals married at age 15-19. These findings may help the policy makers to take decisions regarding shifts in the age at marriage of women precisely. A decline in the proportion married from 0.45 to 0.40 will help Bangladesh to achieve replacement level of fertility, while a decline to 0.3 will help Bangladesh to gain third phase of fertility transition (WPP 2010). On the other hand, if we consider the abortion index from 0.99 to 0.95 , then replacement fertility would have been much earlier than expected.

Table 9. Simulation for proportion married at age 15-19 and its impact on fertility of Bangladesh (BDHS 2014)

\begin{tabular}{ccccc}
\hline $\begin{array}{c}\text { Proportion } \\
\text { married at 15- } \\
\text { 19 }\end{array}$ & ASMFR & TMFR & $\boldsymbol{C}_{m}$ & $\begin{array}{c}\text { Model } \\
\text { TFR }\end{array}$ \\
\hline 0.44 & 255 & 3.22 & 0.714 & 2.18 \\
0.43 & 263 & 3.26 & 0.706 & 2.16 \\
0.42 & 269 & 3.29 & 0.699 & 2.14 \\
0.41 & 276 & 3.32 & 0.692 & 2.12 \\
0.40 & 283 & 3.35 & 0.685 & 2.09 \\
0.39 & 290 & 3.39 & 0.678 & 2.07 \\
0.38 & 297 & 3.43 & 0.670 & 2.05 \\
0.37 & 305 & 3.47 & 0.662 & 2.03 \\
0.36 & 314 & 3.51 & 0.654 & 2.00 \\
0.35 & 323 & 3.56 & 0.646 & 1.98 \\
0.34 & 332 & 3.61 & 0.637 & 1.95 \\
0.33 & 342 & 3.66 & 0.629 & 1.93 \\
0.32 & 353 & 3.71 & 0.619 & 1.89 \\
0.31 & 364 & 3.77 & 0.610 & 1.86 \\
0.30 & 376 & 3.82 & 0.601 & 1.84 \\
\hline
\end{tabular}

\section{Discussion and conclusion}

The purpose of this paper is to assess the current fertility level through use of proximate determinants, but the analysis of proximate determinants shows a discouraging level of TFR. This is puzzling in view of the fact that during the last decade Bangladesh has made significant progress in all the MDGs indicators with the exception of TFR. Even poverty level has declined from $30.5 \%$ to $24.7 \%$ present in 2015 . Per capita income also increased. Female enrolment in educational institutions from primary to tertiary level also increased significantly. At secondary and higher secondary level, there is a gender equity. At the tertiary level about $40 \%$ of the enrolled students are 


\section{2 • Romanian Journal of Population Studies • Vol. XII, No. 1}

female students. There are about 90 universities in the private sector while in government sector the number of universities is 37 . About $40 \%$ of the female labour force is in the labour market. Per capita income along with infant, under five and maternal mortality also declined significantly. Despite all these positive factors, TFR in Bangladesh has stalled again. A close analysis shows that the proportion of individuals married at adolescent ages and abortion are the two noisy factors, which may be responsible for this.

The application of the Bongaarts model (1978) suggests that most of the fertility declines in recent era are attributable to family planning and lactational infecundability. The present analysis suggests that though the fertility transition of Bangladesh sharply declined up to period 1993-94, thereafter TFR did not change as much as expected trends had forecast. Prior to 2007 contraception played its role adequately as major fertility inhibiting factor. According to our analysis lactational infecundity has been placed in the second highest fertility inhibiting factor. The fertility-inhibiting effect of postpartum infecundability as found in Bangladesh is similar to the pattern found in most traditional societies (Erfani and McQuillan 2008). Lengthy breastfeeding is common in Bangladesh along with presence of exclusive breastfeeding. Both culture and the current health policy in Bangladesh favour universal and prolonged lactation, which improve both the health condition of children and the widening of birth intervals (Islam et al 2011). Modernization and increased use of contraception might be related to the declining trends in breastfeeding and post-partum amenorrhea; previous studies (Salway et.al. 1993) identified increased use of contraception as the most important determinant for the declining trend in post-partum amenorrhea.

Due to legal and social constraints, national level data on induced abortion are not available and its effects remain almost unknown. Nevertheless, verification from hospital and clinic records and other sources suggests that induced abortion is not rare, even though it is done under the name of menstrual regulation in Bangladesh (Islam et al 1998).

However, the impact of nuptiality patterns on the aggregate fertility level is not the expected one. While a slight increase has been observed in age at first marriage during the last two decades, the proportion married at age 1519 is still alarming. There has been little decline in the proportion of individuals married at age 15-19. Child marriage is still prevalent. The BDHSs show about two thirds got married before reaching the age of 16 years (which is the legal age at marriage). Another important finding of the study is the change in agespecific fertility patterns, which indicate that childbearing is taking place at an earlier age that had been found in previous studies. As the desired level of 
fertility is declining and there is little change in age at marriage, it appears that couples tend to reach their desired number of children in quick succession immediately after marriage and then regulate fertility at older ages with little effect on the replacement fertility. Compared to neighbouring South Asian countries, the proportion of married individuals, ASFR, ASMFR are highest in Bangladesh for age group 15-19.

The simulation of proportion of married individuals in the adolescent age group suggests new policy implications to achieve replacement fertility. The prevailing cultural and social norms in Bangladesh are unlikely to permit a change in the proportion of non-married individuals beyond a certain limit and the prospect for an immediate rise in the age at marriage for females does not seem to be very optimistic (Islam et al 1998). At the same it also raises questions regarding the effects of the change in socio-economic conditions such as females' enrolment in education, entry into the labour market, increased per capita income and high, gender equity in higher secondary education and about $40 \%$ enrolment of females in tertiary education, which should have produced gradual changes in reproductive behaviour. The fact that these effects were not visible is puzzling. Was this an artefact of data produced by the BDHSs? It is therefore warranted to ask what went wrong with Bangladesh, how the problem should be tackled, and what might happen next? The demographic projection suggests that if Bangladesh would have achieved replacement fertility in 2015 it would have a 25 years window of demographic dividend. If replacement fertility is achieved later, then the window would be of 20 years. The duration of the demographic dividend depends on when we achieve replacement fertility, and a shorter window is depriving the country from the benefit of replacement fertility.

This study has shed further investigation on the fertility transition in Bangladesh. Nevertheless, the extent to which Bangladeshi women are making their own decisions, the mechanisms of decision making among the couples, the institutional framework by which the government implemented its policies, and the question of achieving replacement fertility in Bangladesh and benefit of demographic dividend are among the questions remain to be explored and policy prescriptions should be followed accordingly in the coming years. 
$124 \cdot$ Romanian Journal of Population Studies • Vol. XII, No. 1

\section{References}

Alkema, L., Raftery, A., Gerland, P., Clark, S., Pelletier, F., Buettner, T., and Heilig, G. (2011). "Probabilistic Projections of the Total Fertility Rate for All Countries". Demography 48(3): 815-839.

Bongaarts, J. (1978) "A framework for the analysis of the proximate determinants of fertility". Population and Development Review 4(1): 105-132.

Bongaarts, J. (1982) "The fertility-inhibiting effects of the intermediate fertility variables". Studies in Family Planning 13(6/7): 179-189.

Bongaarts, J., Frank, O., and Lesthaeghe, R. (1984) "The proximate determinants of fertility in sub-Saharan Africa". Population and Development Review 10(3): 511-537.

Bongaarts, J., and Potter, R. G. (1983). Fertility, biology and behavior: Analysis of the proximate determinants of fertility. New York: Academic Press.

Bongaarts, J., and Watkins, S. C. (1996). "Social interactions and contemporary fertility transitions". Population and Development Review 22(4): 639-682.

Caldwell, J. C., Khuda, B. E., Caldwell, B. C., I. Pieris, I., and Caldwell, P. (1999) The Bangladesh fertility decline: An interpretation. Population and Development Review 25(1): 67-84.

International Centre for Diarrhoeal Disease Research, Bangladesh (ICDDR,B) (1996) Fertility Intention and Subsequent Abortion in Matlab, Bangladesh. ICDDR,B, Dhaka.

Islam, M. A., Islam, M. M., and Chakraborty, N. (2002) Achieving Replacement Level Fertility in Bangladesh: Challenges and Prospects. Paper 18, CPD-UNFPA Programme on Population and Sustainable Development, CPD, Dhaka.

Islam, M. M., Dorvlo A. S. S., and Al-Qasmi, A. M. (2011) "Proximate determinants of declining fertility in Oman in the 1990s". Canadian Studies in Population 38(3-4): 133-152.

Islam, M. M., Mamun, A. A., and Bairagi, R. (1998) "The proximate determinants of fertility in Bangladesh: Evidence from BDHS 1993-94". Asia-Pacific Population Journal 13 (3): 3-22.

Islam, M. N., and Islam, M. M. (1993) "Biological and behavioral determinants of fertility in Bangladesh: 1975-1989". Asia-Pacific Population Journal 8(1): $3-18$.

Kabir, M., and Uddin, M. M. (1987) "Effect of nuptiality, contraception and breast-feeding on fertility in Bangladesh". Journal of Biosocial Science 19(3): 345-350.

Johnston, H. B., and Hill, K. H. (1996) "Induced Abortion in the developing world: Indirect estimates". International Family Planning Perspectives 22(3): 108-114. 
National Institute of Population Research and Training (NIPORT), Mitra and Associates, and ICF International (2016). Bangladesh Demographic and Health Survey 2014. Dhaka, Bangladesh and Rockville, Maryland, USA.

National Institute of Population Research and Training (NIPORT), Mitra and Associates, and ICF International (2013). Bangladesh Demographic and Health Survey 2011. Dhaka, Bangladesh and Calverton, Maryland, USA.

Rabbi, A. M. F. (2015). "Do increasing legal age at marriage and increased use of contraception will matter to achieve demographic goal: Revisiting the role of proximate determinants in Bangladesh". Bangladesh Journal of Scientific Research 28(1): 27-34.

Salway, S., Roy, N. C., and Koenig, M. A. (1993) Levels and Trends in Post-partum Amenorrbea, Breastfeeding, and Birth: Results from WFS surveys. WFS Comparative Studies 40. Voorburg (Netherlands): ISI.

Simmons, G. B. (1985). Theories of fertility, in Fertility in Developing Countries: An Economic Perspective on Research and Policy Issues. London: Macmillan Press.

Stover, J. (1998). "Revising the Proximate Determinants of Fertility Framework: What Have We Learned in the Past 20 Years?". Studies in Family Planning 29(3): 255-267.

United Nations, Department of Economic and Social Affairs, Population Division (2011). World Population Prospects: The 2010 Revision, Volume I: Comprehensive Tables. New York, NY: UN.

United Nations, Department of Economic and Social Affairs, Population Division (2017). World Population Prospects: The 2017 Revision, Methodology of the United Nations Population Estimates and Projections, Working Paper No. ESA/P/WP.250. New York: United Nations.

Wang, S. X., Chen, Y. D., Charles, H. C., Chen, R. W., Rochat, L.P., and Rider, R. V. (1987). "Proximate determinants of fertility and policy implementation in Beijing". Studies in Family Planning 18 (1): 222-228. 
